
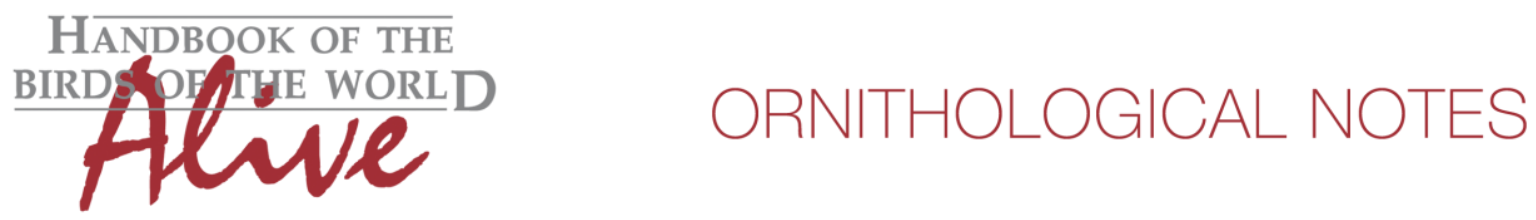

\title{
Notes on the vocalizations of Rufous-fronted Thornbird (Phacellodomus rufifrons)
}

Peter Boesman

In the following we briefly analyze and compare voice of the different races of Rufousfronted Thornbird (Phacellodomus rufifrons). We also try to quantify the extent of any vocal differences using the criteria proposed by Tobias et al. (2010), as a support for taxonomic review. We have made use of sound recordings available on-line from Xeno Canto (XC).

Song is similar to several other members of the genus, a loud series of nearly-identical staccato notes. In typical song of a single individual, series starts with well-spaced notes, slowly accelerating, intensifying and increasing in pitch, then slowing, decreasing and fading. Often however, at least two birds sing together, and when excited, deliver very long series of nearly-identical notes, at some point ending abruptly.

When comparing inornatus/castilloi with all other races, it is quickly obvious that song is much higher-pitched. We have therefore measured all basic parameters in a number of recordings, in order to quantify differences:

inornatus/castilloi $(n=7)$

Max. freq.

Min freq.

Freq. range of single note

Note length

\# notes to reach max pitch

song length

\# of notes

pace*

peruvianus $(n=3)$

Max. freq.

Min freq.

Freq. range of single note

Note length

\# notes to reach max pitch

song length

\# of notes

pace

sincipitalis $(n=3)$

Max. freq.

Min freq.

Freq. range of single note

Note length

\# notes to reach max pitch

song length

\# of notes

pace
$4450-4900 \mathrm{~Hz}$

$950-1150 \mathrm{~Hz}$

$3050-3900 \mathrm{~Hz}$

$0.05-0.07 \mathrm{~s}$

4-6 (only measured for typical rising/falling songs)

2.4-3.08s (idem)

15-19 (idem)

0.13-0.19

$1680-2200 \mathrm{~Hz}$

$650-850 \mathrm{~Hz}$

$900-1500 \mathrm{~Hz}$

0.075-0.11s

6 (only measured for typical rising/falling songs)

$3.4 \mathrm{~s}$

15

0.23

$2000-2100 \mathrm{~Hz}$

$800-1000 \mathrm{~Hz}$

$1200-1250 \mathrm{~Hz}$

$0.07-0.115 \mathrm{~s}$

4-5 (only measured for typical rising/falling songs)

6.4-8s

27-32

$0.23-0.25$ 


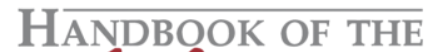 \\ wirof \\ Alve}

specularis/rufifrons $(n=5)$

Max. freq.

Min freq.

Freq. range of single note

Note length

\# notes to reach max pitch

song length

\# of notes

pace

* pace measured here as period: duration of note + pause

\section{ORNITHOLOGICAL NOTES}

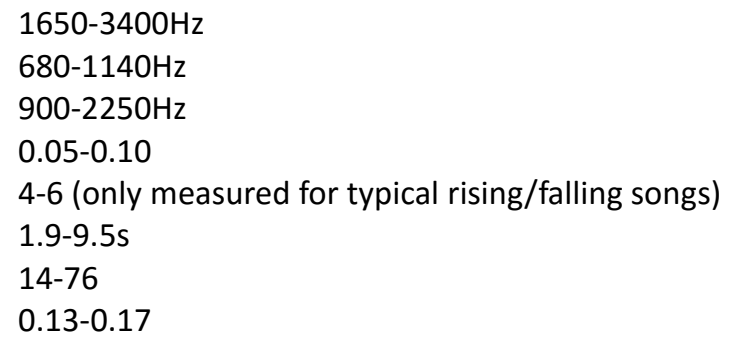

There seem to be three vocally different groups (Fig. 1).
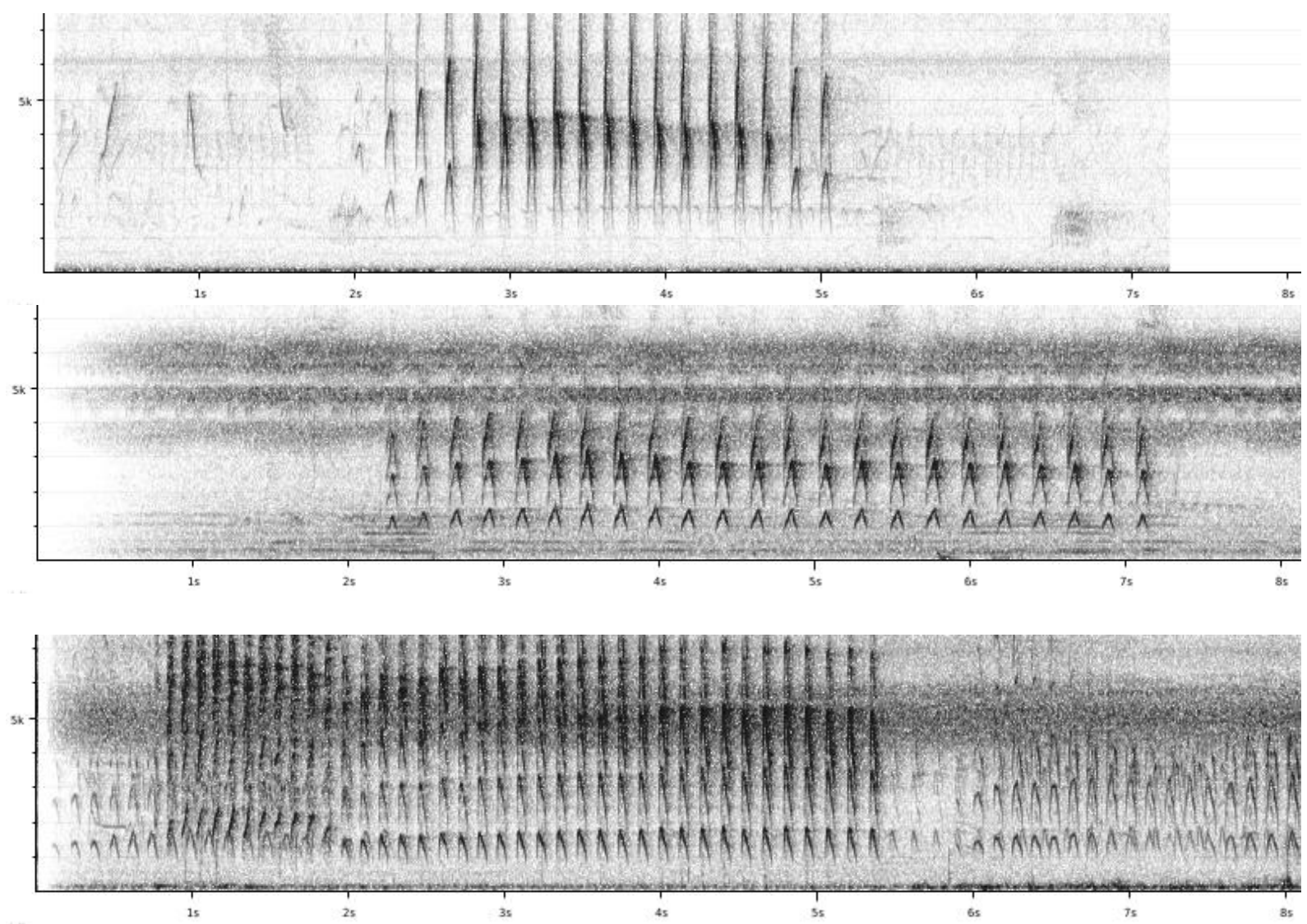

Figure 1: typical song of group 1 inornatus/castilloi (top), group 2 peruvianus/sincipitalis (middle) and group 3 specularis/rufifrons (bottom)

The largest difference is between inornatus/castilloi and peruvianus/sincipitalis, as the former has clearly higher max. freq. (score 3) with weaker harmonics and notes with a high frequency range (score 2), shorter note lengths (score 1) and a faster pace of delivery (score 2). This would lead to a total vocal score of about 5 when applying Tobias criteria. 
specularis/rufifrons shares the low frequency with peruvianus/sincipitalis, but the faster pace with inornatus/castilloi.

If inornatus/castilloi has to be compared with all others in one single enlarged group, then only the higher max. freq. and frequency range remain, leading to a total score of 4 or 5 .

This note was finalized on 16th April 2015, using sound recordings available on-line at that moment. We would like to thank in particular the many sound recordists who placed their recordings for this species on XC.

\section{References}

Tobias, J.A., Seddon, N., Spottiswoode, C.N., Pilgrim, J.D., Fishpool, L.D.C. \& Collar, N.J. (2010). Quantitative criteria for species delimitation. Ibis 152(4): 724-746.

\section{Recommended citation}

Boesman, P. (2016). Notes on the vocalizations of Rufous-fronted Thornbird (Phacellodomus rufifrons). HBW Alive Ornithological Note 95. In: Handbook of the Birds of the World Alive. Lynx Edicions, Barcelona. (retrieved from http://www.hbw.com/node/932000 on 20 July 2016). 